\title{
CONTROL AND THE DIGITAL COMPUTER: THE EARLY YEARS
}

\author{
Stuart Bennett \\ Department of Automatic Control \& Systems Engineering, The University of Sheffield, \\ Mappin Street, Sheffield, S1 3JD, UK, Email: $\underline{\text { s.bennett@sheffield.ac.uk }}$
}

\begin{abstract}
During the years 1950-1970 there was extensive development of control theory and its application. This paper explores the influence of the rapid development of the digital computer and associated enabling technologies on the field of control systems. A brief outline of digital computer and control theory development is given followed by an account of the effect of the digital computer on process control applications. Copyright (C) 2002 IFAC
\end{abstract}

Keywords: history, digital computer, process control, control theory

\section{INTRODUCTION}

Text books published around 1950 expounded the frequency domain techniques which had been used during the war for the design (by trial and error) of linear single variable systems. However, as many of contributors to the conferences of 1951 (at Cranfield, UK) and 1953 (New York, USA) explained, typical real-world problems were non-linear, complex, multivariable, many involving discrete as well as continuous data; they also expressed the need for optimum not just adequate controller performance. Extending frequency domain methods to provided new design tools, and exploiting the supporting technologies of the analogue computer and rapidly improving electronic components, appeared to be the agenda for the next decade. In June 1948, at the University of Manchester (UK), stored program electronic computer ran, initiating the digital computer age and creating a new agenda for control systems research and application.

News of digital computer developments - Giant Brains they were called in many popular articlestogether with the accounts of the contributions of control practitioners to the development of fire control (gun control) systems during the 1939-1945 war, led to a widespread debate on automation. There was a flood of books, talks on the radio, and articles in magazines and newspapers; leading newspapers of record, The Times in the UK and the
New York Times in the USA devoted considerable column inches to the debate. Governments, in both the USA and the UK, instituted enquiries into the subject and professional engineering institutions began to recognise automatic control as a specific sub-discipline worthy of the formation of sections (Bennett, 1993). A report produced, in 1956, for the UK government saw a combination of mechanisation, automatic control and the newly emerging digital computer as providing the means to overcome labour shortages and keep the economy growing and developing. This perceived need for automation led to both private and public investment in automatic control systems and the associated enabling technologies. The "cold war" led governments, particularly in the USA and the USSR to invest heavily in technologies which supported missile and aerospace developments. Machine based computing devices, both analogue and digital, had proved their value as aids to military activity during the 1939-1945 and hence computing technologies were seen as important areas for investment.

The paper outlines he development of digital computers (section 2) and then briefly comments on the relationship between control theory developments and computers (section 3 ). In section 4 the impact of computer and control theory developments on an important application area, process control, is discussed. 


\section{DIGITAL COMPUTER}

\subsection{Early Computers}

Alan Turing's Colossus, operational at the end of the 1939-1945 war, was the worlds first functioning electronic digital computer and Britain's lead in digital computation was retained when, in June 1948, the Manchester University Mk 1 became the first stored program digital computer to run, this was followed by EDVAC (modelled on the American EDSAC design) running at Cambridge University (UK) in June 1949. The first commercial digital computer was the Ferranti Mk1 (based on the Manchester University design) which became operational in February 1951 (shortly before the first UNIVAC computer ran in the USA) and was followed in September 1951 by LEO 1 based one the Cambridge EDVAC design (LEO-Lyons Electronic Office-was built for the Lyons Catering Company). Although further Ferranti and LEO machines were designed and built (the last of LEO machines, a LEO III was delivered in 1972) and the British Government continued to support various computer developments the massive military investment in research funding and purchases in the USA quickly swept away Britain's lead in digital computing.

Of concern to both manufacturers and customers was the reliability of the early computers. Experience with the special purpose ENIAC computer which had 18,000 vacuum tubes, well in excess of the 3,000 to 5,000 tubes of the early commercial computers, showed that by running vacuum tubes continuously and with low filament voltages (reduced from 6.3 volts to 5.7 volts) a reasonable level of performance could be achieved - a failure rate of one tube every 2 days. One early user of the UNIVAC 1, Metropolitan Life Insurance reported $81 \%$ availability, however, this was considered very high for the early 1950 s (Edwards, 1996). The drive for reliability was led by the military and IBM demonstrated, with its FSQ-7 computer, what could be achieved if cost what not a prime consideration. The FSQ-7 formed the heart of the SAGE (Semi Automatic Ground Environment) computerised air defence system. IBM built 56 FSQ7, the first of which went into service about 1956 and the last machines were delivered in 1962. The FSQ-7 weighed 300 tons, had 58,000 vacuum tubes and cost $\$ 30$ million: it achieved its high reliability both through careful component selection and also because of its duplex structure. The average down time for the FSQ-7 was 4 hours per year.

The transistor offered the opportunity for very much reduced power consumption but the germanium point contact transistor of the early 1950s was not considered to be as reliable as the existing valve technology so although some early experimental transistorised machines were produced it was not until the latter part of the decade that commercial transistorised computers began to appear. Among the early experimental computers were the Bell Laboratories, TRADIC, built, for the US Air Force in 1954 and in the same year IBM produced a transistorised version of the 604 electronic calculator in which 1250 valves were replaced by 2200 transistors giving a reduction in power consumption of $95 \%$ and a $50 \%$ reduction in the space required [Braun, $1982 \# 191$, (Logue, 1998)]. An experimental transistor based computer, TX-0, was built at MIT in 1954 which was based on surface barrier transistors pioneered by the Philco company of Philadelphia. The Burroughs company also developed computer systems using the transistor technology which were used to control the launch of ATLAS intercontinental ballistic missiles. The largest discrete transistor computer built, containing 70,000 transistors, was the LARC system begun in 1957 and completed in 1960.

In the UK, F.C. Williams and T. Kilburn designed experimental transistorised machines the first of which ran in November 1953 and the second in April 1955. The second machine formed the basis of the MV950 built by Metropolitan Vickers, probably the first commercial transistor based computer when the production model was run in 1956; six MV950s were built.

\subsection{Commercialisation}

In the USA, the Government, although keeping some developments secret, permitted extensive disclosure of computing advances and use of these ideas for the production of commercial computers (Edwards, 1996). Two of the major government funded projects, the Whirlwind project and the subsequent SAGE (Semi-automatic Ground Environment) system, resulted in several major technical advances: magnetic core memory, video displays, light guns, algebraic computer language, graphic displays, simulation techniques, synchronous parallel logic, analogue-to-digital and digital-to-analogue techniques, duplexing, multiprocessing and networks. IBM, as the major contractor for the SAGE computer systems was able, through the experience and knowledge gained, establish itself as the major computer builder and achieve market dominance in the early 1960s. IBM along with several other companies who had built computers for military use and hence had experience of dealing with real-time operations and interrupts saw that there might be a market for their designs in the process control field and they began to seek this market either directly or by collaborating with the existing process control companies. In the USA the Taylor-RamoWooldrigde company led the way to process control applications and in the UK it was the Ferranti Company who recognised that this market could provide an outlet for a civil version of its military computers. 


\subsection{The Rise of the Minicomputer}

IBM and other mainstream manufacturers who switched to transistor based computers did so without changing the basic design. With the IBM 709 (and its transistor based successor, the 7090) came the concept of using a separate processor the "channel" to handle the input and output operations. As the range of $\mathrm{I} / \mathrm{O}$ devices and their requirements increased the channel processors began to become as complex and as powerful as main processor and as expensive. The cycle was broken by the Ben Gurley of the fledgling Digital Equipment Corporation with the PDP-1 produced in 1959. The Digital Equipment Corporation was formed in 1957 by Kenneth H Olsen and Harlan Anderson and the company's first computer, the PDP-1 was offered for sale in 1959. The design of the PDP-1 was heavily influenced by the TX-0 computer designed and built MIT's Lincoln Laboratory. The PDP-1 was an 18 bit word length with direct memory access, that is data from $\mathrm{I} / \mathrm{O}$ devices could be transferred directly to the core memory without passing through the CPU registers. It also had up to sixteen levels of priority interrupts. The PDP-1 sold for $\$ 120000$ and about fifty were sold. Other machines followed including a larger computer the PDP-6 which was used at MIT for the initial time-sharing developments and was the forerunner to the successful PDP-10.

The minicomputer revolution was led by the Digital Equipment Corporation (DEC) with the PDP-8 introduced in 1965 and selling originally for \$18 000 . The PDP- 8 was the first computer to reveal the size of the market for small, cheap machines and over 50,000 systems were sold. It was the successor to the PDP-5 introduced in 1963 and designed by Edson de Castro. Like the PDP-5 it had a 12 bit word length, used germanium transistors and physically was packaged into a series of modules each of which performed defined logic functions, these modules were plugged into a wire wrapped back plane. The 12 bit word length restricted the amount of memory which could be addressed-the instruction format allowed for a seven bit address, that is 128 wordshowever, this limitation was overcome by using indirect addressing in which the address in the instruction was an address in memory which stored the actually address of the operand, thus giving a 12 bit address value. In addition the memory was divided into pages - exploiting the fact that instructions which crossed page boundaries did not occur frequently. Two other factors help with the popularity of the PDP-8: it was supplied with a Model 33 ASR teletype from the Teletype Corporation, and also with the versatile DECtape-a magnetic tape drive that was closer to the floppy disk drives of modern computers than the tape drives on the mainframes.

The Digital Equipment Corporation did not have the minicomputer market to itself, Scientific Data
Systems with its SDS-910 and SDS-920 computers, General Electric with the GEPAC4000 series machines and the Computer Control Corporation (bought by Honeywell in 1996) with its 16 bit DDP116 were all early competitors. By the end of the 1960s the number of competitors in this market was growing rapidly - it is estimated that 100 companies (or divisions of established companies) offered minicomputers between 1968 and 1972. The TTL (transistor-transistor based) integrated circuit offered cheap, easy to use components, and hence to barriers to entering the market were low. (Ceruzzi, 1998)

\section{CONTROL THEORY}

Accounts of the foundation of modern control theory have been given by Dorato (1996) and by MacFarlane (1979). MacFarlane argues that the nature of problems considered important by governments in the USA and the USSR - launch and control of missiles and space vehicles - determined the direction of control theory research. The problems, essentially ballistic in nature, meant that accurate mechanical models of the systems being controlled were available and also that the systems could be fitted with high precision measuring instruments. In addition many of the performance criteria were "economic" in nature-minimum fuel for example. The nature of the problems moved attention from the frequency response methods back to the use of differential equations and the simplest way to formulate the problem for solutions, using either analogue or the newly emergent digital computer, was to use sets of first-order differential equations. Henri Poincare had recognised the value of using sets of first-order differential equations and this approach had been used by Lyapunov in his study of stability. The approach was taken up by Richard Bellman, working for the RAND Corporation.

The RAND Corporation (Research ANd Development) was formed in 1948 as a not-for-profit corporation to promote "public welfare and security of the United States of America", and its formation arose from a recognition by leading military officers of the effectiveness of operational research methods used during the 1939-1945 war and a wish to ensure that the military had access to a robust general science of warfare from which winning strategies could be developed. In reality the Corporation turned in to a "university without students" and undertook wide ranging studies covering mathematics, economics, computer science, engineering, management and social science (Hounshell, 2000), (Levien, 2000). Richard Bellman played a leading role in the mathematics programme and in particular in his study of dynamic optimisation under constraint which led to his development of dynamic programming. 
Bellman's use of the concept of the state in the formulation of control and decision problems, and the publication in 1956, in the USSR, by L. S. Pontryagin of a paper which enunciated what is now known as the 'maximum principle', led to work on the linear multivariable feedback control problem using the state point of view. Major advances in understanding came from the work of R.E. Kalman in a series of papers from 1957 onwards. Much of Kalman's work was supported by contracts from the US Air Force's Air Research and Development Command, a group formed shortly after the conversion of Project RAND into a private not-forprofit corporation and again shows the extent of military interest and financial support of control systems.

Using Bellman's, Pontryagin's and Kalman's methods to design control systems for real applications was non-trivial and required in the late 1950s and early 1960s large financial resources. The cold war ensured that these resources were available for aerospace applications and the reported success in such applications led to attempts by large process companies to use the methods for industrial problems. The problems which arose in industrial applications led Howard H. Rosenbrock (1962; 1966; $1969)$ to investigate methods of reducing the interaction in a multivariable problem to such an extent that single-loop techniques could be applied and his pioneering work led to a resurgence of interest in frequency response methods. Rosenbrock expressed the view in 1977 that the difficulties experienced in late 1960s arose from the attempt to "turn engineering problems into mathematical problems, which could be solved algorithmically" and that this part of "modern control" would "in the end turn out to be a historical accident", the techniques suited the guidance problem and the and the available computing facilities (Rosenbrock, 1977).

\section{THE DIGITAL COMPUTER AND PROCESS CONTROL}

\subsection{Monitoring and Supervision}

By 1950 the major industrial instrument companies-Foxboro, Taylor Instruments, Leeds \& Northrup, Bristol, George Kent-all sold pneumatic PID controllers. Skilled instrument mechanics were needed to build and maintain these controllers and they were also physically large. New companies entering the market offering electronic versions of the PID controller. The process industry was suspicious of electronics - there were concerns about the reliability of electronic valves - and fire hazards in the petro-chemical industry posed a problem for electronic systems. The electronic instruments, however, were physically smaller than their pneumatic counterparts and had increased bandwidth. During the 1950s the instrument manufacturers responded to the competition with major advances in the design and construction of pneumatic instruments; they reduced the number of moving parts and the physical size of pneumatic devices. They also began to develop their own electronic PID controllers.

Controllers were only one product area for the major instrument companies, the capture and recording of data from the plant was important area of business and as plant instrumentation became more extensive they had been seeking ways of reducing the costs of recorders and displays by using sequential switches to multiplex many instrument reading to a single recorder. They quickly recognised the potential of the newly emerging digital technology as providing a means of improving the recording and displaying of plant information, not as a means of providing automatic control. The early systems, such as Taylor's Trans Scan Log control system made use of the peripheral devices which had been developed for use with digital computers: electric typewriters, printers, scanners and analogue-to-digital converters.

The idea of process control by digital computer was raised, in 1948, in an article in the Scientific American, and again in 1949 by G.S. Brown, D.P. Campbell and H.T. Marcy; a more extensive proposal for supervisory control of chemical processes was made in 1951 by M.V. Long and E. G. Holzmann of the Shell company. The Hughes Aircraft Company are credited with the first supervisory control application with their Digitrac computer, which, in 1954, was used for an experimental scheme for the supervisory control of an automatic pilot system. The first industrial computer installation was that of a Daystrom computer for plant monitoring at the Louisiana Power \& Light Company, at Sterling, Louisiana which went live in September 1958. The first industrial digital computer based control system was the catalytic polymerisation unit of the Port Arthur (Texas) plant of the Texaco Company which went on-line in March 1959. It used a RamoWooldridge RW-300 computer and had 103 process measurements and 14 control outputs of which five, controlling the reactor feed valves, were direct digital control outputs, all the other outputs were set point adjustments for analogue controllers. The RamoWooldridge Company, an advanced scientific and engineering services company, had been involved since 1953 in the USAF ballistic missile programme, but was looking to diversify into civil applications and had initiated the project with the Texaco company in 1956. In 1958 it merged with Thompson Products, a supplier of precision parts for automobiles and aircraft, to form the ThompsonRamo-Wooldridge Company and this company remained until the mid-1960s the major supplier of digital computers and computer control systems for 
industrial applications (Stout and Williams, 1995), (Dyer, 2000).

Interest in computer control grew rapidly and by 1971 there were 41 manufacturers of process control computers. The established industrial instrument companies responded rapidly to the threat to their markets. As early as 1960 Bailey, Foxboro (with RCA), Leeds \& Northrup (with Philco) and Minneapolis-Honeywell were offering computer based systems. The existing instrument companies had the advantage not only of knowing the market and having a good understanding of process control, but also of having developed interface technologies such as analogue-to-digital signal conversion for use with the data logging systems which they began to introduce in the mid-1950s. However, they all lagged in the market behind Thompson-Ramo-Wooldridge in terms of the number of installations until the mid1960s.

\subsection{Direct Digital Control (DDC)}

These early computer control schemes had a large element of process monitoring with data reduction and plant performance calculations for use by managers and steady state optimisation of plant performance with either direct adjustment of set points or advice to operators on plant settings. Beginning in 1955, Instruments \& Automation, widely read by engineers in the process industries, carried series of articles on Digital Automation: the main thrust of the articles was explaining how digital computers operated and how they might be used to assist managers but some articles did consider the use of digital computers for feedback control. The first use of a digital computer for fully direct control of a process was initiated by Imperial Chemical Industries (ICI) who began work in 1959 with the Ferranti Company on a Direct Digital Control (DDC) scheme for a soda ash plant at Fleetwood, Lancashire. The system was based on the Ferranti 200 computer which had a ferrite core memory, programmed by inserting pegs into a plug board, each peg representing one bit in a memory. The computer could handle 256 input measurements and 120 control loops-224 and 98 of which respectively were used in the Fleetwood system which went live in November 1962 and ran for three years (Bennett, 1988). This was not strictly the first DDC to operate, since the public mention of the project in 1961 prompted engineers at the Monsanto Chemical Company to quickly investigate direct digital control and in collaboration with TRW they installed a trial DDC system on an ethylene unit at Monsanto's Texas City plant which went live in March 1962 but which was run on a trial basis for only three months (Stout and Williams, 1992; Stout and Williams, 1995).

In 1964, reviewing the state of computer control applications in the chemical industry, Theodore J. Williams of the Monsanto Company, saw DDC as being technically feasible and desirable but needing the development of suitable hardware (Williams, 1964). By 1965, over 1000 digital computers were in use in industrial control applications but it is difficult to estimate how many incorporated DDC, however, judging by the number of papers which began to appear in the late 1960s the inclusion of DDC in computer control schemes must have been increasing. The advantages of DDC were that the cost-per-loop did not increasing linearly with the number of loops as with analogue control and also that making modifications only involved changing the code not rewiring as was required with analogue systems. There were, however, concerns about the reliability of digital computers and many of the early DDC schemes included back-up analogue controllers for critical loops and electronic PID controllers were quickly modified to provide automatic change-over to analogue back-up should the digital computer fail to update the controller output within a specified time interval. This strategy was strongly promoted by the established instrument manufacturers since it maintained their market for analogue devices. The established companies also developed special process control languages for programming the digital computer: these languages enabled the user to set up the system as if it was an analogue system.

\subsection{Dynamic Optimisation}

The first industrial applications of digital computers for control used steady-state optimisation and adaptive methods based on pre-determined schedules. There were large cost gains to be made from improving the dynamic performance of process operations and in the 1959-1960 the IBM Company supported work by Kalman on dynamic optimisation of chemical plants (Kalman and Koepcke, 1959; Kalman, et al., 1959). In the early 1960s work began on schemes to apply optimal feedback control to industrial plants to provide dynamic optimisation, with the aim of having the process "follow the economic optimum path during startup and shutdown and while recovering from upsets" (Williams, 1964). These attempts quickly revealed major problems: insufficiently accurate plant models and difficulties in formulation appropriate performance indices. The digital computer, combined with classical statistical analysis methods, offered a means of improving the accuracy of plant models and during the 1960s there was a rapid growth in work on parameter estimation techniques, not only in control but in many other areas of science and engineering. However, even if accurate models of industrial plants could be obtained direct application of optimal control design produced controllers of complexity equivalent to the complexity of the process. The complexity of model and controller were such that they exceeded the capability of the available computers. Williams 
(1964) argued for work on finding what degree of approximation in dynamic models used for controller design was acceptable and forecast that dynamic optimisation of chemical processes would not be achieved before 1972 .

Although direct application of optimal control methods to industrial processes was no immediately feasible, the work of Kalman and Bucy in solving the Wiener filtering problem using multivariable time response approach quickly led to industrial implementation. One early application involved using an IBM 1710 computer system to control a paper making machine, Karl J. Åström, who then worked in the IBM Nordic Laboratory was responsible for the control design (Åström, 1964).

\section{CONCLUSIONS}

A cursory comparison of the proceedings of the Cranfield Conference of 1951 with those of the First IFAC Congress of 1960 immediately shows the extent of the growth of the field in less than a decade and this growth continued during the 1960s. W. Findeisen, in 1966, reported that basic control theory was being taught in the majority of undergraduate level courses in electrical and mechanical engineering in most countries in the world and that courses on modern control methods were being offered at post-graduate level in many universities in many countries. The reasons for this rapid development are inevitably complex, but it is clear that military competition between the USA and the former USSR, the consequent government support and funding of digital technologies and of systems and control theory, played a major role. The close links in the USA between the military, industry and universities encouraged a rapid transfer of information and ideas to private companies for commercial use and the more open society in the USA encourage public debate on industrial use of automation.

\section{REFERENCES}

Åström, K.J. (1964). Control problems in papermaking. In Proceedings of the IBM Scientific Computing Symposium on Control Theory and Applications, 135167.

Bennett, S. (1988). Real-time Computer Control: An Introduction. Prentice Hall, Hemel Hempstead.

Bennett, S. (1993). A History of Control Engineering 19301955. Peter Peregrinus, Stevenage.

Ceruzzi, P.E. (1998). A History of Modern Computing, Cambridge, MA.

Dorato, P. (1996). Control history from 1960. In Proceedings of the 13th Triennial World Congress of the International Federation of Automatic Control,

Dyer, D. (2000). The limits of technology transfer: civil systems at TRW, 1965-1975. In: Systems, Experts, and Computers: The Systems Approach in Management and Engineering World War II and
After. (A. C. Hughes and T. P. Hughes) (Ed)), 359384. The MIT Press, Cambridge, MA.

Edwards, P.N. (1996). The Closed World: Computers and the Politics of Discourse in Cold War America. The MIT Press, Cambridge, MA.

Findeisen, W. (1966)

Hounshell, D.H. (2000). The medium is the message, or how context matters: the RAND Corporation builds an economics of innovation, 1946-1962. In: Systems, Experts, and Computers: The Systems Approach in Management and Engineering World War II and After. (A. C. Hughes and T. P. Hughes) (Ed)), 255310. The MIT Press, Cambridge, MA.

Kalman, R.E. and R.W. Koepcke (1959). The role of digital computers in dynamic optimization of chemical reactions. Proceedings of Western Joint Computer Conference.

Kalman, R.E., et al. (1959). Optimal control of chemical and petroleum processes. Joint Symposium on Instrumentation and Computation in Process Development and Plant Design, London.

Levien, R.E. (2000). RAND, IIASA, and the conduct of systems analysis. In: Systems, Experts, and Computers: The Systems Approach in Management and Engineering World War II and After. (A. C. Hughes and T. P. Hughes) (Ed)), 433-461. The MIT Press, Cambridge, MA.

Logue, J.C. (1998). From vacuum tubes to very large scale integration: a personal memory. IEEE Annals of the History of Computing 20, 55-68.

MacFarlane, A.G.J. (1979). The Development of Frequency-Response Methods in Automatic Control. IEEE Transactions on Automatic Control AC-24, 250-265.

Rosenbrock, H.H. (1962). Distinctive problems of process control. Chemical Engineering Progress, 58, 43-50.

Rosenbrock, H.H. (1966). On the design of linear multivariable control systems. 3rd IFAC World Congress, London.

Rosenbrock, H.H. (1969). Design of multivariable systems using the inverse Nyquist array. Proceedings of the Institution of Electrical Engineers, 116, 1929-1936.

Rosenbrock, H.H. (1977). The future of control. Automatica, 13, 389-392.

Stout, T.M. and T.J. Williams (1992). The Computer Control Pioneers: A history of innovators and their work. Instrument Society of America, Research Triangle, NC.

Stout, T.M. and T.J. Williams (1995). Pioneering work in the field of computer process control. IEEE Annals of the History of Computing, 17, 6-18.

Williams, T.J. (1964). Control theory and applications in chemical process control. Proceedings of the IBM Scientific Computing Symposium on Control Theory and Applicatons, 103-134. Yorktown Heights, NY, IBM. 